\title{
A Comparison of Epidural Ropivacaine $0.75 \%$ and Bupivacaine 0.5\% with Fentanyl for Elective Lower Limb Othopaedic Surgeries
}

\author{
Dr. Sonali Kagade ${ }^{1}$, Dr. Jay Kothari ${ }^{2}$
}

\begin{abstract}
Early studies suggested that Ropivacaine had clinical advantages over Bupivacaine with respect to cardiotoxicity and motor block, and that it was suitable for epidural lower limb orthopaedic surgeries. This study was set up to compare epidural 0.75\% Ropivacaine with a popular Bupivacaine/Fentanyl mixture for lower limb orthopaedic surgeries.
\end{abstract}

Keywords: Bupivacaine, Ropivacaine, Fentanyl, Epidural, Anaesthesia

\section{Methods and Materials}

Sixty men undergoing lower limb orthopaedic under epidural anaesthesia were randomly allocated to receive 20 $\mathrm{mL}$ of either $0.75 \%$ Ropivacaine or $0.5 \%$ bupivacaine plus Fentanyl $100 \mu \mathrm{g}$. Supplementation with $2 \%$ plain lidocaine was used where necessary. Times were recorded for onset of sensory block, density and duration of motor block, and the need for supplementation.

\section{Results}

There was no difference between the groups in the time (mean [SD]) to achieve sensory blockade to cold to T4 (ropivacaine 15.8 [5.6] min, bupivacaine/fentanyl 18.7 [9.1] min, $P=0.13$ ) or to S1 (Ropivacaine 18.3 [4.6] min, Bupivacaine/Fentanyl 17.4 [7.6] $\min , P=0.59$ ), or in the need for supplementation. However, Ropivacaine produced a motor block that was denser (median Bromage score Ropivacaine 3, Bupivacaine/Fentanyl 1.5, $P=0.0041$ ), and of longer duration (ropivacaine 237 [84] min, bupivacaine/fentanyl 144 [76] $\min , P<0.0001$ ).

\section{Conclusions}

This study suggests that epidural $0.75 \%$ Ropivacaine without opioid may be used as an alternative to Bupivacaine $0.5 \%$ with Fentanyl for elective lower limb orthopaedic surgeries, but it does not induce anaesthesia any faster and may result in a denser, more prolonged, motor block.

\section{References}

[1] Knudsen, K., Beckmann Suurkula, M., Blomberg, S., Sjovall, J., Edvardsson, N. Central nervous and cardiovascular effects of i.v. infusions of ropivacaine, bupivacaine and placebo in volunteers. Br J Anaesth. 1997;78:507-514.

[2] Scott, D.B., Lee, A., Fagan, D., Bowler, G.M.R., Bloomfield, P., Lundh, R. Acute toxicity of ropivacaine compared with that of bupivacaine. AnesthAnalg. 1989;69:563-569.

[3] Brockway, M.S., Bannister, J., McClure, J.H., McKeown, D., Wildsmith, J.A.W. Comparison of extradural ropivacaine and bupivacaine. $\mathrm{Br} J$ Anaesth. 1991;66:31-37.

[4] Morrison, L.M.M., Emanuelsson, B.M., McClure, J.H. et al, Efficacy and kinetics of extradural ropivacaine: comparison with bupivacaine. $\mathrm{Br} J$ Anaesth. 1994;72:164-169. 